\title{
Totemismo e tabu hoje ${ }^{156}$
}

\section{Cecília Rodrigues Ribeiro ${ }^{157}$}

Este estudo faz parte de uma pesquisa maior de doutorado que se iniciou em antropologia social na École des Hautes Études en Sciences Sociales (EHESS), em 2015 e que atualmente segue sob a orientação da professora, pesquisadora e psicanalista Cristina Lindenmeyer (Centre National de la Recherche Scientifique, Université Paris7, Centre de Recherches Psychanalyse et Médecine). Trata-se de um estudo interdisciplinar, na área de antropologia psicanalítica, que tem por base teórica inicial o texto freudiano "Totem e Tabu" (1912/1913).

A análise que se propõe nesta apresentação é: 1) um mergulho sobre a importância do texto na obra freudiana e para a psicanálise; 2) entender a necessidade de uma releitura partindo das novas bases teóricas da antropologia. Para isso, faremos um resumo sobre o totemismo enquanto conceito antropológico.

\section{1) Totem, tabu, as origens da humanidade e a sociedade do século $\mathrm{XX}$}

O texto publicado em 1913 representa um cruzamento das disciplinas sociais e psicanalíticas. É de comum conhecimento que a obra é uma resposta à Jung e sua teoria do inconsciente coletivo, noção pensada diferentemente por Freud através daquilo que ele descreve como filogenética. Assim como altera os rumos da psicanálise argumentando que a teoria também se presta a considerações sociais, o que pode ser uma réplica à Adler. $\mathrm{O}$ fato é que o texto se inscreve, junto a outros, naquilo que Birman (2019) aponta como crítica da modernidade, expondo a primeira interdição sexual e inserindo a morte em um local privilegiado na cena originária da sociedade (talvez já elaborando o texto marco de 1920).

\footnotetext{
${ }^{156}$ Apresentado em Trabalhos livres no II Simpósio Bienal SBPSP "Fronteiras da Psicanálise: a clínica em movimento" no dia 28 de agosto de 2020.

${ }^{157}$ Mestre em psicopatologia e psicanálise Université Paris-Diderot, doutoranda pela École des Hautes Études en Sciences Sociales e Université Sorbonne Nord.
} 
Freud aponta, no início (1912), o problema da psicologia social e do distanciamento da antropologia com a psicanálise, procurando aquilo que ele chamou de significado original do totemismo através dos vestígios remanescentes nas ações voltadas ao totem. Nota-se desde as primeiras linhas que Freud era evolucionista (como todos em seu tempo) e, assim, ele acreditava que a sociedade na qual ele vivia era um exemplo de evolução cultural e civilizatória e, por consequência, as outras que o precederam eram estágios anteriores a esta.

Seguindo, então, os estudos da antropologia evolucionista, as primeiras partes do texto se consagram a uma análise etnológica do totem e o do tabu, o primeiro como um animal, vegetal ou fenômeno natural que mantém uma relação social, por vezes mais forte que a sanguínea, e que determinam o clã e a exogamia do casamento; o segundo como uma antiga restrição sagrada que carrega consigo uma noção de transmissibilidade e que leva o indivíduo a adotar ações purificatórias negativas ou positivas.

A cena primitiva do totemismo, o 'mito' (expressão lacaniana de 1966 para a ficção de Freud), se inicia com os irmãos, que admiravam e temiam o alfa, e que se deixam levar pelo ódio (Zafiropoulos, 2016). Eles se organizam em grupo para matá-lo e em seguida comê-lo; se repartem as mulheres criando as regras de aliança. A eliminação do líder tinha

\footnotetext{
como objetivo o acesso ao gozo pleno junto às fêmeas, e, estando o pai primevo morto e devorado, tal acesso fica franqueado (...). Ao se voltarem às fêmeas, percebem-se rivais (...). Caso uma nova disputa se estabeleça, gerando um novo líder, o pai primevo estaria redivivo, exceção que exerce o monopólio do gozo, produzindo uma maioria insatisfeita; (...). A mudança de paradigma pressupõe um corte nesse presente maciço. (Malcher \& Freyre, 2016)
}

A interdição sexual é repetida através da sistematização totêmica e da criação de tabus. A veneração e o medo são traduzidos nas interdições e destacase, aqui, a ambivalência de ambos. O momento de dividir a carne do pai se caracteriza como a primeira festa da humanidade: a refeição totêmica, uma reprodução da cena original que trata da culpa do parricídio. O inimigo se torna ainda mais forte depois de morto: a ordem paterna começa (em relação à desordem anterior). 
Para Assoun (2019), trata-se de um mito científico: Freud pensa ter encontrado a origem do elo social. Mesmo se o estudo fora publicado em 1913, ele teve início no ano anterior, o que acentua ainda mais o valor de estudo: uma análise progressiva de dados. Para além deste fato, à partir do começo do século XX e até o final de sua vida Freud vai procurar novos sujeitos que se relacionam com a antropologia, mitologia, religião, arte e cultura ${ }^{158}$. Dentre eles, "O interesse científico da psicanálise" que foi escrito, explica Villa (2016), na mesma época que a terceira parte de "Totem e Tabu", ou seja, no momento em que Freud elabora o 'mito'. Neste segundo texto de 1913 percebe-se uma relação ritmada entre um interesse de explorar outra disciplina para em seguida dialogar e receber a outra disciplina no campo analítico, muito mais do que pensar em aplicações da psicanálise. Lindenmeyer (2020) explica que o terreno da pulsonalidade está marcado nestes textos (pensar a relação entre renúncia pulsonal e a invenção do social em "Totem e Tabu”, por exemplo), mesmo se em 1913 todo o desenvolvimento da metapsicologia freudiana ainda não tinha se confirmado.

\section{2) O totemismo, ontem e hoje}

Muito se poderia falar ainda sobre este texto fundador de Freud (e a literatura sobre este sujeito é rica). Mas por hora, voltemos para o conceito de totemismo, em seu contexto primário. Considera-se que o termo totemismo tenha sido criado pelo etnólogo MacLennan, em 1841, um dos pioneiros da corrente evolucionista na antropologia (Rosa, 2003). Tylor (1871) e Wundt (1874) ${ }^{159}$ vão, em seguida, teorizar o animismo. Nos tempos ditos de ouro do totemismo, dois grandes antropólogos discutiam o sistema totêmico e suas relações com a religião, a magia e o casamento: Durkheim $(1898,1912)$ e Frazer (1887, 1890). Nesta época, um artigo de Spencer e Gillen (1899), impactou toda a comunidade antropológica, pois foi considerada como a primeira verdadeira descrição detalhada de uma sociedade totêmica.

Frazer fundará, partindo desta publicação de 1899, a antropologia religiosa, em uma obra de mais de 2.0oo páginas sobre o tabu, o sagrado e as interdições. De fato, a maior referência de Freud para iniciar Totem e Tabu em 1912 é Frazer

\footnotetext{
${ }^{158}$ O termo cultura é comumente traduzido por civilização nas obras americanas e latino-americanas e que se remete ao "processo de modernização do social" segundo Birman, 2019 p. 40.

${ }_{159}$ A obra do pai da psicologia foi analisada por Freud principalmente no que concerne o tabu.
} 
de 1910. Isso quer dizer que o totemismo é visto como o culto coletivo de um totem que tem origem uterina. Entre as variações teóricas da origem da religião, da magia e do totem, Frazer admite (mas somente a partir de 1910) que eles podem existir em uma mesma sociedade, como sinal de evolução para a conversão de uma religião. Ou seja, religião e totemismo podem se cruzar em uma mesma sociedade, mas somente em um sentido evolutivo. A exogamia se originaria para evitar parentes consanguíneos de se reproduzir, o que conduziria à lei da interdição do incesto (Frazer, 1910).

Uma discussão teórica muito aprofundada entre estes dois autores não nos cabe aqui, mas é importante ressaltar que existem variações e diferenças marcantes entre eles e uma das mais importantes é a implicação ou não da exogamia no totemismo (Achimastos, 2012). Outro ponto importante é a diversificação à qual se propõe o autor francês. Seus textos enumeram incontáveis formas e tipos de totemismo (Durkheim, 1902), abrangendo várias manifestações diferentes o que desembocará na primeira virada do totemismo, com o funcionalismo. Nesse sentido, Boas se indaga se todos os sistemas totêmicos se igualam em sua origem (1911). Radcliffe-Brown (1929) demonstra a diversidade das manifestações totêmicas e propõe uma definição geral de natureza psicológica para o totem, abrindo caminho para a crítica levistraussiana.

Por fim, os incontáveis desdobramentos (subseções) dos clãs nas descrições etnológicas se confundem, explica Lévi-Strauss, com os grupos totêmicos. Estes não têm nenhuma relação com as classes matrimoniais e que, ao final, não apresentam nenhuma relação direta com as filiações totêmicas. Para preservar a confirmação do totemismo, continua o autor, nega-se o pluralismo da realidade. Se, ao contrário, prioriza-se a homogeneidade e a regularidade dos fatos, deve-se renunciar ao totemismo como síntese da realidade (Lévi-Strauss, 1962).

Esse breve resumo da teoria totêmica se fez necessário para entender onde se encontra o texto de Freud e onde se encontra a comunidade antropológica hoje. Não somente não se entende mais o totemismo como parte de uma evolução religiosa (o que denota do evolucionismo ${ }^{160}$ ), mas e principalmente, a noção em si de uma categoria 'totemismo’ é ilusória. O casamento e a exogamia não são

\footnotetext{
${ }^{160}$ De fato, atualmente, toda teoria que se exprime em um sentido evolucionista deve se corrigir. Priorizase as relações de uma unidade elementar com outra, ou seja, a sociedade é descrita, analisada e pensada pelo prisma estruturalista.
} 
mais vistos como ligados ao totemismo haja vista a multitude de classes. Um sistema totêmico exprime um sentimento de pertencimento ao clã. É uma produção cultural, política e uma expressão social que deve ser analisada em sua singularidade, como o mito, o rito, a língua, etc.

Deve-se ressaltar a capacidade de pesquisador de Freud: ele leu e analisou as maiores obras da época. Mas se antes os etnólogos tinham dificuldade em dialogar com Freud, pois o mesmo correlacionava o totemismo e o sistema de tabus em uma mesma relação (quer dizer, relacionados à interdição e à exogamia), hoje o texto se encontra desatualizado, ao menos no que tange a literatura antropológica. O conceito de totemismo está completamente desacreditado. Como esperar um diálogo com as disciplinas humanas e sociais se não fizermos um novo estudo e análise densos sobre o tema? Tal qual Freud fez lendo a obra rica e detalhada de Frazer e seus contemporâneos. Este estudo é um convite a esta nova reflexão, uma discussão que deveria se iniciar a partir das estruturas sociais e suas relações. Para além de um olhar que devolva a sexualidade das mulheres na cena primária (Jacques-André, 2009; Héritier, 1996), para além de entender a complexidade de cada sociedade sem o julgamento evolucionista dos tempos modernos, deve-se re-significar o totem como expressão simbólica dentro de um contexto delimitado.

\section{Referências}

Achimastos, M. (2012). Durkheim et Frazer: un débat sur le totémisme. L'Année sociologique, 2012/2 (Vol. 62), p. 313-327. https://www.cairn.info/revue-lannee-sociologique-2012-2-page-313.htm

André, J. (2009). La sexualité féminine. Paris: Presses Universitaires de France. Assoun, P. (2019). Freud: Totem et tabou. Entrevista. Disponível em: https://www.youtube.com/watch?v=gyWpZDgQgDA

Birman, J. (2019). Mal-estar na atualidade: a psicanálise e as novas formas de subjetivação. Rio de Janeiro: Civilização brasileira.

Boas, F. (1911). The origin of totemism. Journal of the American Folklore, Boston, vol. XXIII, p. 392-393. 
Durkheim, É. (1898). La prohibition de linceste et ses origines. L'Année sociologique, 1, 1-70.

Durkheim, É. (1902). Sur le totémisme. L’Année sociologique, 5, 82-121.

Durkheim, É. (1912). Les Formes élémentaires de la vie religieuse. Le système totémique en Australie. Paris: Alcan.

Frazer, J. (1887). Totemism. Édimbourg: A. \& Ch. Black.

Frazer, J. (1890). The Golden Bough. A Study in Comparative Religion. London: Macmillan, $1^{\text {a }}$ edição, volume 2.

Frazer, J. (1998). Totemism and Exogamy. A Treatise on Certain Early Forms of Superstition and Society. London: Macmillan (Trabalho original publicado em 1910).

Freud, S. (2012). Totem e tabu. In S. Freud, Obras Completas Sigmund Freud (P. C. L. Souza, trad., Vol. 11). São Paulo, SP: Companhia das Letras. (Trabalho original publicado em 1913).

Héritier, F. (1996). Masculin, Féminin. La pensée de la différence. Paris, O. Jacob.

Lacan, J. (1966). Écrits. Paris : Éditions du Seuil.

Lévi-Strauss, C. (1986). Le Totémisme aujourd'hui, Paris, PUF (Trabalho original publicado em 1962).

Lindenmeyer, C. (2020). Séminaires. Université Sorbonne Paris Cité (USPC) Université Paris - Diderot (Paris 7)

Radcliffe-Brown, A. (1956). Structure and Function in Primitive Society. London: Cohen and West, (Trabalho original publicado em 1929).

Rosa, F. (2003) L'âge d'or du totémisme: Histoire d'un débat anthropologique (1887-1929). Paris: Éditions de la Maison des sciences de l'homme.

GILLEN F.; SPENCER W. (1899). The Native Tribes of Central Australia. London: MacMillan and Co.

Malcher, F.; Freire, A. (2016). Laço social, temporalidade e discurso: do Totem e tabu ao discurso capitalista. Ágora: Estudos em Teoria Psicanalítica, 19(1), 6984. https://doi.org/10.1590/S1516-14982016000100005

Tylor, E. (1871). Primitive Culture. Researches into the Development of Mythology, Philosophy, Religion, Art and Custom. London : John Murray. 
Villa, F. (2016). Totem et Tabou: une méthode pour linterdisciplinarité?. Research in Psychoanalysis, 21(1), 9a-20a. https://www.cairn.info/revueresearch-in-psychoanalysis-2016-1-page-9a.html

Wundt, W. (1906). Volkerpsychologie. Leipzig: Verlag von Wilhelm Engelmann. (Trabalho original publicado em 1874).

Zafiropoulos, M. (2016). Ce que Lacan disait de Totem et Tabou. Research in Psychoanalysis. Volume 21. https://www.cairn.info/revue-research-inpsychoanalysis-2016-1-page-117a.htm 